\title{
Prevention and Control of Birth Defects in China: Achievements and Challenges
}

Birth defects, including congenital structural or functional abnormalities, remained a primary cause of child mortality and morbidity and represented a significant clinical and public health challenge. Annually, 3\%-6\% of infants, nearly 8 million newborns, were born worldwide with a serious birth defect, among those more than $90 \%$ are in low and middle-income countries (1).

In China, birth defects affected an estimated 5.6\%, approximately 900,000, newborns each year and were the leading cause of infant mortality and a major cause of morbidity (2). To raise awareness of birth defects, to develop and implement primary prevention programs, and to expand referral and care services, the Chinese government declared the September 12 as the "National Birth Defects Prevention Day" at the Second International Conference on Birth Defects and Disabilities in the Developing World which held in Beijing in 2005.

China has continuously improved the laws and regulations and has carried out a series of major projects related to the prevention and control of birth defects. As a result, the preventive measures to prevent birth defects have been continuously strengthened. Nearly 102 million childbearing women took folic acid free of charge from 2009 to 2018, 83.49 million planned pregnancy couples received free pre-pregnancy health examinations in 2010-2018. The screening rate for neonatal genetic or metabolic diseases reached $97.5 \%$ in 2017. As of 2018, about 1.65 million couples in 10 southern provincial-level administrative divisions (PLADs) had received free thalassemia screening. The treatment of 72 types of major birth defects such as congenital heart disease has been incorporated into critical illness insurance program. Through unremitting efforts, the prevention and treatment of birth defects has achieved remarkable achievements.

The child mortality rate caused by birth defects has also decreased significantly. For example, the birth defects induced mortality rate of children under 5 years of age reduced from $3.5 \%$ in 2007 to $1.6 \%$ in 2017 . The incidence of some major birth defects is decreasing year by year. For example, the incidence of perinatal neural tube defects decreased from 27.4 per 10,000 in 1987 to 1.5 per 10,000 in 2017, a decrease of $94.5 \%$. The incidence of fetal edema syndrome (severe $\alpha$ thalassemia) in Guangdong and Guangxi dropped from 21.7 and 44.6 per 10,000 in 2006 to 1.93 and 3.15 per 10,000 in 2017, respectively, a decrease of $91 \%$ and $93 \%$, respectively (3).

With close attention and strong support from the Chinese government, opportunities to prevent birth defects are abundant in China, but there are also many challenges in the process. The incidence of some major birth defects did not show a significant decrease, such as in congenital heart defects and oral facial clefts (4). In some northern regions, the incidence of neural tube defects remained higher than levels worldwide (5). Although the rate of folic acid use increased dramatically, the percentage of correct use was still low (G). Macrosomia accounted for a high proportion of adverse birth outcomes due to maternal overnutrition and insufficient exercise before and during pregnancy ( 7 ). Meanwhile, the impacts of socioeconomic and environmental changes on child health needed more attention, including pollution following modern industrialization and the increasing number of women of advanced maternal age following the three-child policy. Therefore, government officials, healthcare workers, researchers, and public health practitioners in this field should put more effort into prevention, and comprehensive and integrated efforts need to be taken to accelerate and improve postnatal care, surgical correction, rehabilitation, and social support.

doi: $10.46234 / \mathrm{ccdcw} 2021.191$

Submitted: August 31, 2021; Accepted: September 06, 2021

\section{REFERENCES}

1. Groisman B, Bermejo-Sánchez E, Romitti PA, Botto LD, Feldkamp ML, Walani SR, et al. Join world birth defects day. Pediatr Res 2019;86(1):3 - 4. 
http://dx.doi.org/10.1038/s41390-019-0392-x.

2. Ministry of Health of the People's Republic of China. National stocktaking report on birth defect prevention (2012). Beijing: Ministry of Health of the People's Republic of China. 2012. http://www.gov.cn/gzdt/att/att/site1/20120912/1c6f6506c7f811bacf9301.pdf. (In Chinese).

3. Department of Maternal and Child Health, National Health Commission of People's Republic of China. Report on the development of maternal and child health in China (2019). 2019. http://www.nhc.gov.cn/fys/jdt/201905/bbd8e2134a7e47958c5c9ef032e1dfa2.shtml. [2019-5-27]. (In Chinese).

4. Xu WL, Deng CF, Li WY, Wang K, Tao J, Gao YY, et al. National perinatal prevalence of selected major birth defects - China, 2010-2018. China CDC Wkly 2020;2(37):711 - 7. http://dx.doi.org/10.46234/ccdcw2020.195.

5. Liu JF, Zhang L, Li ZW, Jin L, Zhang YL, Ye RW, et al. Prevalence and trend of neural tube defects in five counties in Shanxi province of Northern China, 2000 to 2014. Birth Defects Res A Clin Mol Teratol 2016;106(4):267 - 74. http://dx.doi.org/10.1002/bdra.23486.

6. Li Q, Wang YY, Guo YM, Zhou H, Wang XB, Wang QM, et al. Folic acid supplementation and the association between maternal airborne particulate matter exposure and preterm delivery: a national birth cohort study in china. Environ Health Perspect 2020;128(12):127010. http://dx.doi.org/ $10.1289 /$ ehp6386.

7. Lin SQ, Chai J, Li JJ, Shang XJ, Pei LJ, Jiang LF, et al. Incidence of macrosomia in rural areas - Henan Province, China, 2013-2017. China CDC Wkly 2021;3(37):788 - 92. http://dx.doi.org/10.46234/ccdcw2021.196.

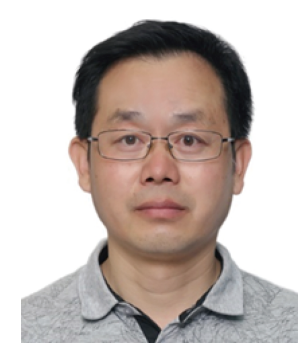

Zhiwen Li, MD, PhD

Deputy Director of Institute of Reproductive and Child Health, Key Laboratory of Reproductive Health, National Health Commission of the People's Republic of China, Peking University, Beijing, China

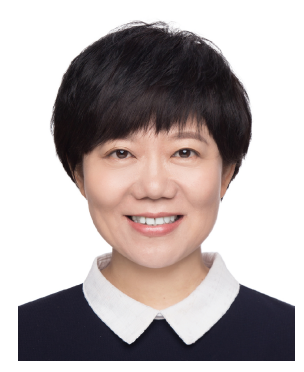

Jiangli Di, MD, PhD

Deputy Director of the Women and Children's Health Monitoring Department, National Center for Women and Children's Health, China CDC, Beijing, China 